\title{
Acute Myocardial Infarction
}

National Cancer Institute

\section{Source}

National Cancer Institute. Acute Myocardial Infarction. NCI Thesaurus. Code C35204.

Necrosis of the myocardium, as a result of interruption of the blood supply to the area. It

is characterized by a severe and rapid onset of symptoms that may include chest pain,

often radiating to the left arm and left side of the neck, dyspnea, sweating, and palpitations. 